\title{
Impact Analysis of Go-Kart Bumper to Frontal Collision for Different Materials
}

\section{P. N. V. Balasubramanyam, B. Nageswara Rao, B. Lakshmana Swamy, Moon Banerjee, Evvala Satya}

Bharath

\begin{abstract}
The very basic inescapable ramification of using automobiles is that from now and then accidents will cause damage to it. In this advanced world, many modern materials have been introduced to the automobile body. A bumper is an edifice structure appertain to the front end and rear end of an automobile that covers the chassis. The bumper and the substructure chassis are the two components that take most of the impetus force during collision conditions. In this work, the bumper of a Go-Kart has been modelled and analysed using ANSYS R19.2 software. The model is analysed in various standard conditions for impact analysis using disparate materials namely Polyethalene, Epoxy Resin And Aluminium Alloy. Various parameters such as total deformation, equivalent stress, equivalent elastic strain have been observed and results were noted. The robustness of the component is determined by pinpointing the fragment or chunk that the breach will occur or where the equivalent stress is elevated when force is attached in front of the Go-Kart. The impact analysis under dynamic loading shows that Expoxy Resin material is more reliable for Go-Kart bumper as it is producing low distortion and has low stress and strain compared to other materials used.
\end{abstract}

KEYWORDS: - Impact; Bumper; Go-Kart; Analysis; Safety; Design.

\section{INTRODUCTION:}

Road accidents can be terrifying occurrence, they are happening every day. Majority of the drivers are perused that they can avoid such threatening conditions. However, nearly 1.3 million of people are either dead or injured in thoroughfare accidents each year, on an average 3,300 accidents per day which became a gigantic issue. One of the aspects contributing to the peril of hazard due to crash is vehicle design. Hence, revamp the design is very predominant. Bumpers are designed to avert or minimize the fleshly damage to the automobile in accidents. A Bumper is horizontal constructionstable or integrated with the front part and at the rare end of an automobile, to absorb impact throughout the collision and to stable the vehicle and to protect the passenger compartment.

Revised Manuscript Received on October 30, 2019.

* Correspondence Author

P. N. V. Bala Subramanyam, Research Scholar, Department of Mechanical Engineering, Koneru Lakshmaiah Educational Foundation, Vaddeswaram, Guntur, Andhra Pradesh, India

B. Nageswara Rao, Professor, Department of Mechanical Engineering, Koneru Lakshmaiah Educational Foundation, Vaddeswaram, Guntur, Andhra Pradesh, India

B. Lakshmana Swamy, Professor, Department of Mechanical Engineering, Koneru Lakshmaiah Educational Foundation, Hyderabad, Telengana,India

Moon Banerjee, Associate Professor, Department of Mechanical Engineering, Koneru Lakshmaiah Educational Foundation, Hyderabad, Telengana,India

Evvala Satya Bharath, Under Graduate, Department of Mechanical Engineering, Koneru Lakshmaiah Educational Foundation, Vaddeswaram, Guntur, Andhra Pradesh, India

(C) The Authors. Published by Blue Eyes Intelligence Engineering and Sciences Publication (BEIESP). This is an open access article under the CC BY-NC-ND license (http://creativecommons.org/licenses/by-nc-nd/4.0/) the bumper and chassis are the master components intrude the impact force.

They enhance the resistivity of all external forces and impulse the required strength to protect the vehicle and minimize the damage.

Bumper is the key feather of all macho looking accessory which is commonly termed as the crash guard of a vehicle. In India bumpers are banned for various disadvantages under section 52 of motor vehicle act and 190/191 of the motor vehicle act, but this work helps in conquer those negative aspects and give a roadmap for fining a better solution and safety of the passengers and the vehicle. They(bumper) additionally protect engine, fuel tank, headlamps, fog lights, indicators, etc.

\section{Go-Kart Bumper:}

Go-Kart bumper is slightly different from the conventional bumpers as it is the low speed vehicle the bumper needs to be designed very accurately considering all the boundary conditions. However, Bumpers are mandatory for every gokart whether it is fully closed or sub divided bumpers should be mounted to the chassis of the Go-kart.
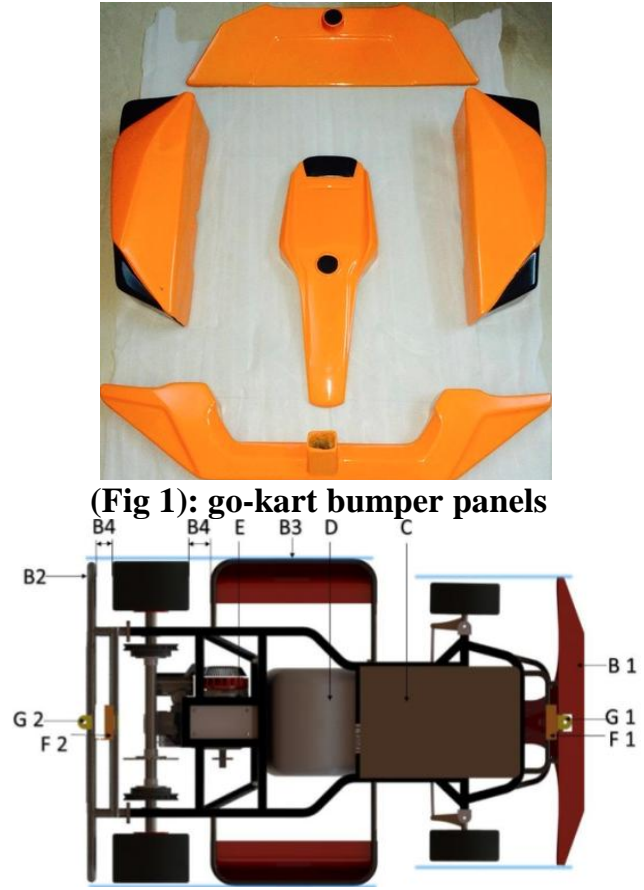

(Fig 2): Demonstrative view of Go-Kart

B1- Front bumper. C- Leg compartment.

B2- Rear bumper. D- Seat compartment.

B3- Side bumper.

E-Engine compartment.

G1- Front Hitch point

F1- Front jack point.

G2-RearHitchpoint.

F2- Rear jack point. 


\section{Impact Analysis of Go-Kart Bumper to Frontal Collision for Different Materials}

B4- Gap between tire and bumper.

\section{DESIGNE:}

In this work ANSYS R19.2 analysis Software have been used to design, model and analysis the impact on the bumper. The software is a mitigated high proficiency analyser which has many discoveries such as 3D designing, Additive Manufacturing, Electro magnetics, Embedded software, Fluids, Optical, Structures, Systems, etc.

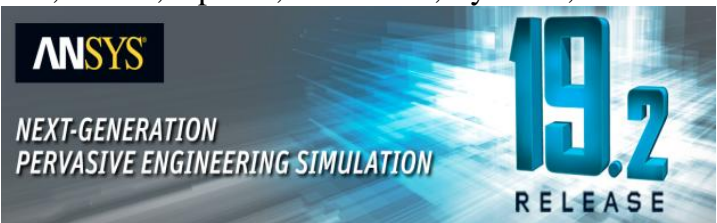

(Fig 3): Official ANSYS R 19.2 Logo

The software is also capable of ECAD-MCAD Import, Comprehensive Multi physics Design Flow, Convenient Slider Bar Meshing, Extensive Libraries for Thermal Physics, Optimization in Icepak, Visualization, Multidomain System Modelling.

\section{DIMENSIONS:}

This workhas taken standard dimensions suggested in FMVSS NO. 581 and IIHS.

\section{MATERIALS:}

1. Polyethylene.

2. Epoxy Resin.

3. Aluminium Alloy

\section{BOUNDARIES:}

1. Rigid body state(wall).

2. Movability or velocity state

(Go-Kart).

3. Fixed body condition(bumper).

\section{MESHING:}

It is a command to be used in the Ansys software which process the component into finest element method. Meshing tool will construct the well organised multiscale measurement and physical solution. Creating the most appropriate mesh leads to easy to the simulation.

\section{RESULTS:}

Final results have been obtained and analysed as shown below

\section{Material-1:}

\section{Polyethylene:}

Total Deformation

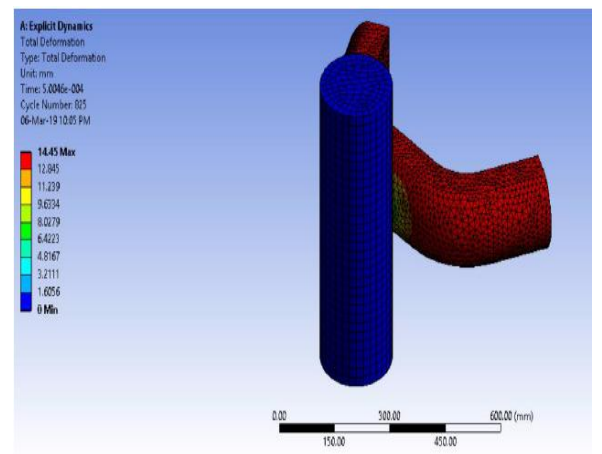

(Fig.4): Total Deformation for polyethylene material

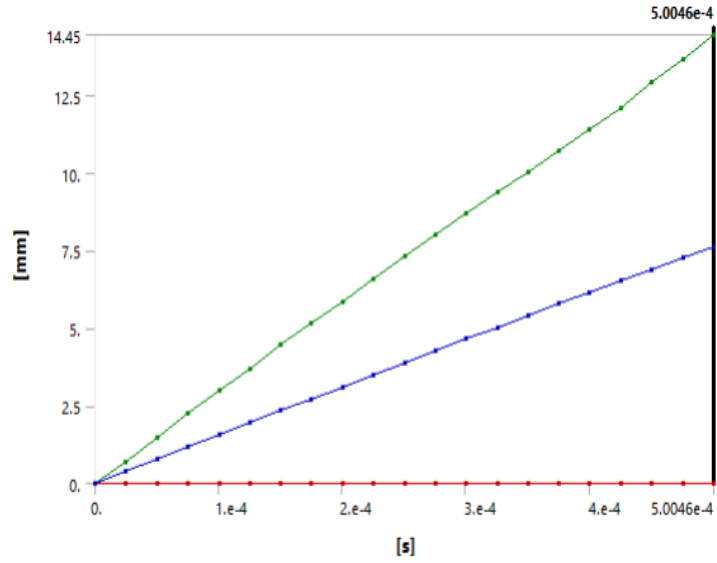

Plot of Total Deformation for polyethylene material EQUIVALENT STRESS:

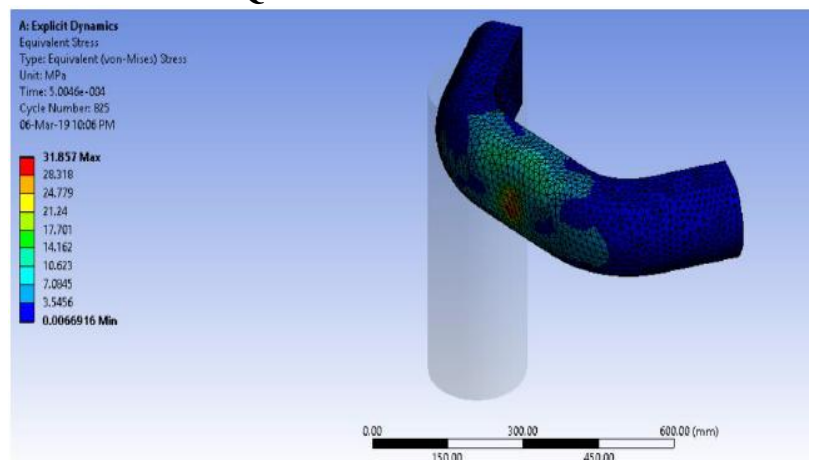

(Fig.6): Equivalent Stress for polyethylene material

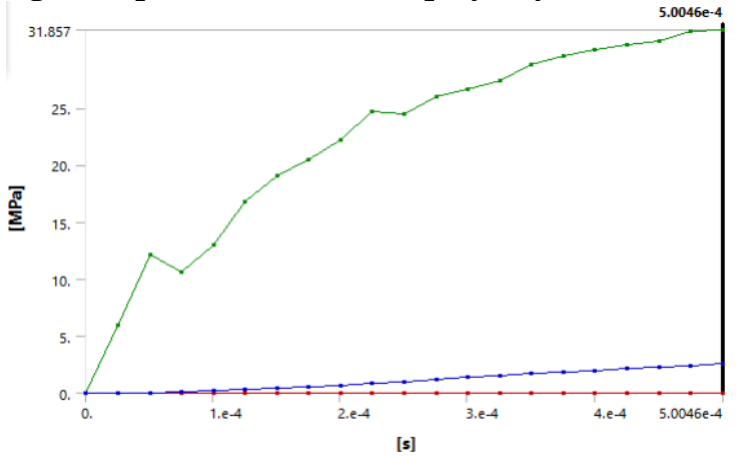

(Fig.7): Plot of Equivalent Stress for polyethylene material

EQUIVALENT ELASTIC STRAIN:

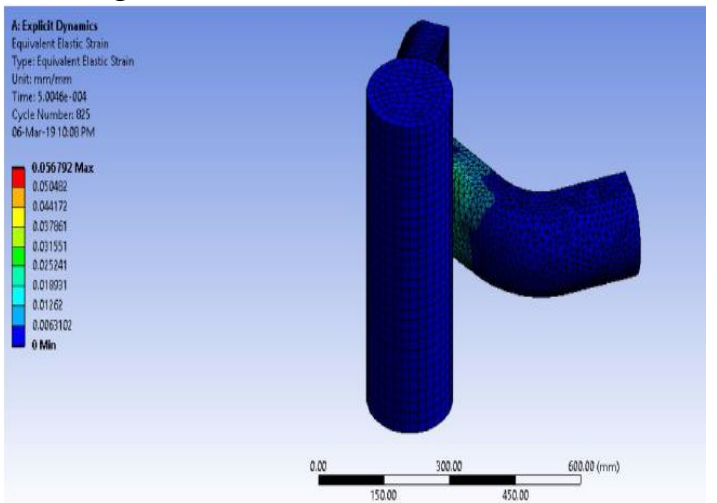

(Fig.8): Equivalent elastic strain for polyethylene material 


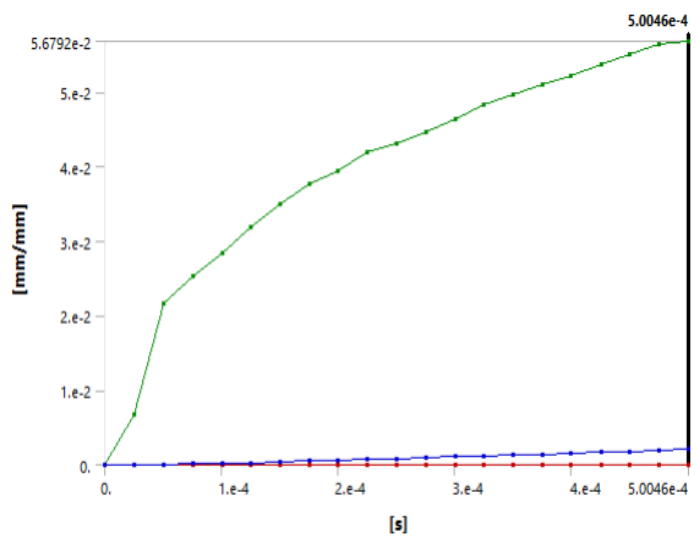

(Fig.9): Plot of Equivalent elastic strain for polyethylene material

\section{Material-2 :}

Epoxy Resin

Total Deformation

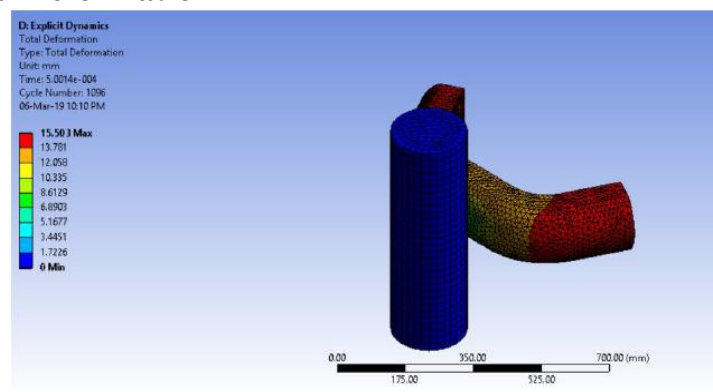

(Fig.10): Total Deformation for Epoxy Resin material

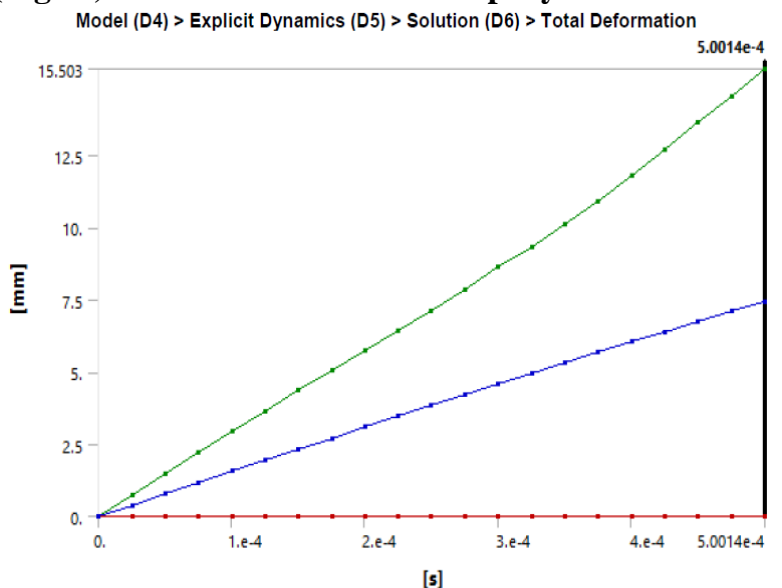

(Fig.11): Plot of Total Deformation for Epoxy Resin material

EQUIVALENT STRESS:

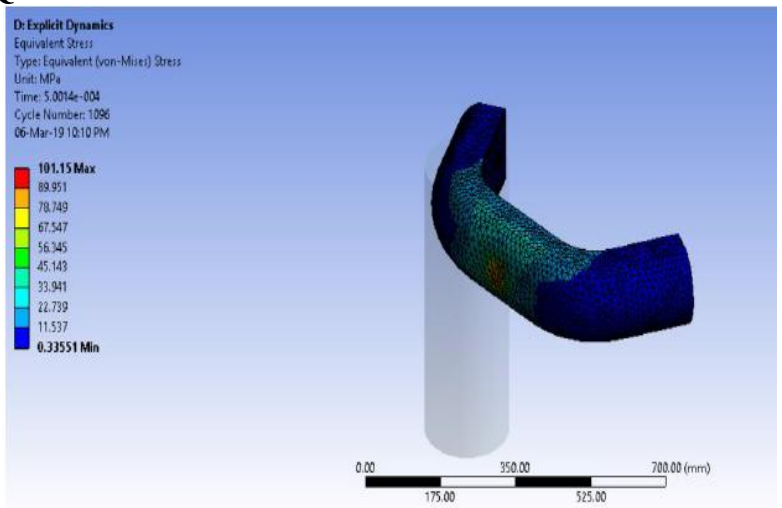

(Fig.12): Equivalent Stress for Epoxy Resin material
(Fig.14): Equivalent elastic strain for Epoxy Resin material

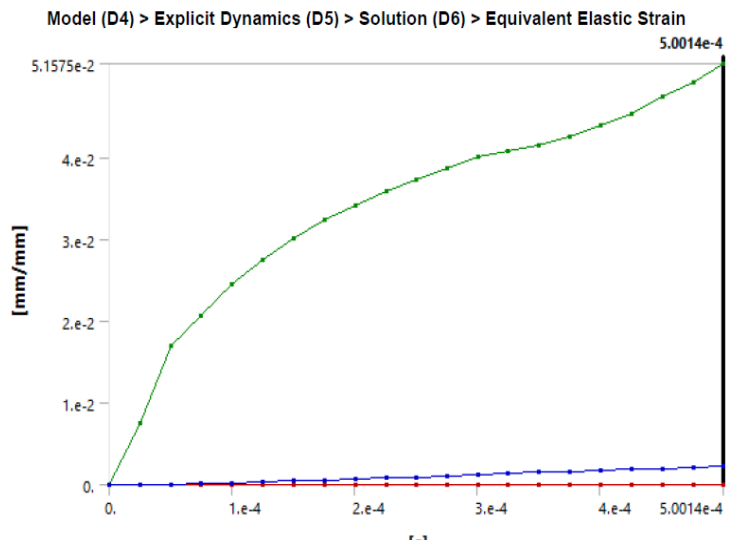

(Fig.15): Plot of Equivalent elastic strain for Epoxy Resin material

\section{Material-3 :}

Aluminium Alloy

Total Deformation

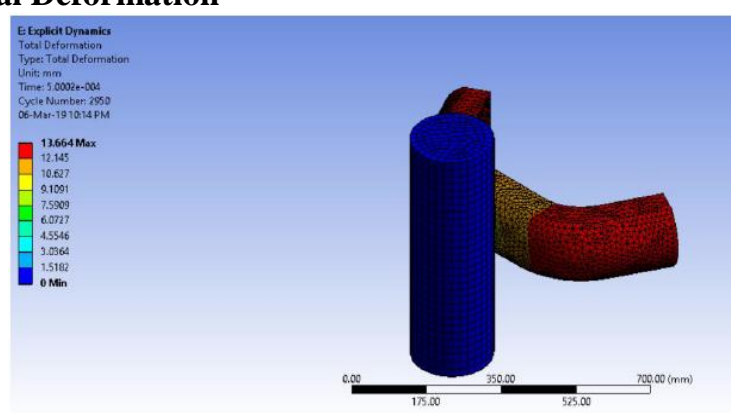

(Fig.16): Total Deformation for Aluminium Alloy material

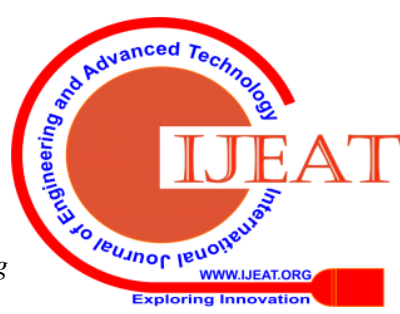




\section{Impact Analysis of Go-Kart Bumper to Frontal Collision for Different Materials}

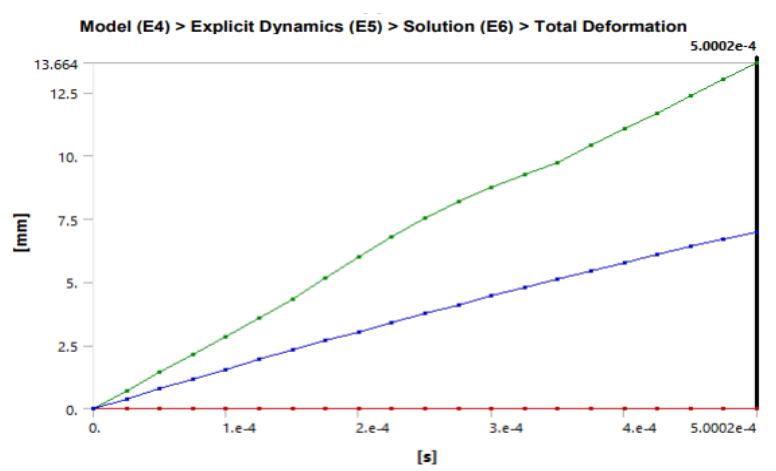

(Fig.17): Plot of Total Deformation for Aluminium Alloy material

EQUIVALENT STRESS:

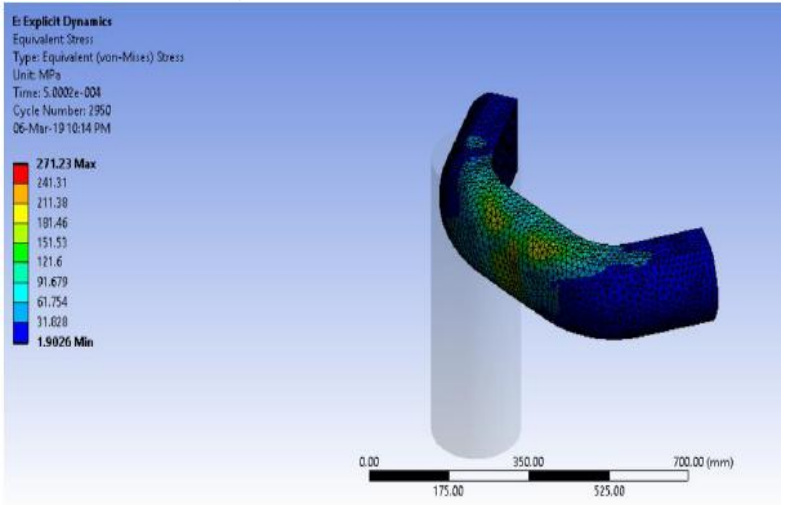

(Fig.18): Equivalent Stress for Aluminium Alloy material

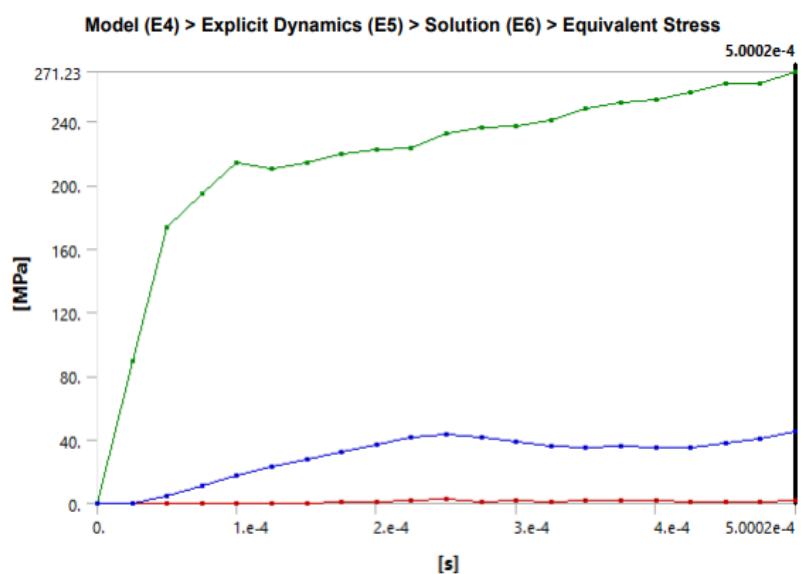

(Fig.19): Plot of Equivalent Stress for Aluminium Alloy material

Equivalent Elastic Strain:

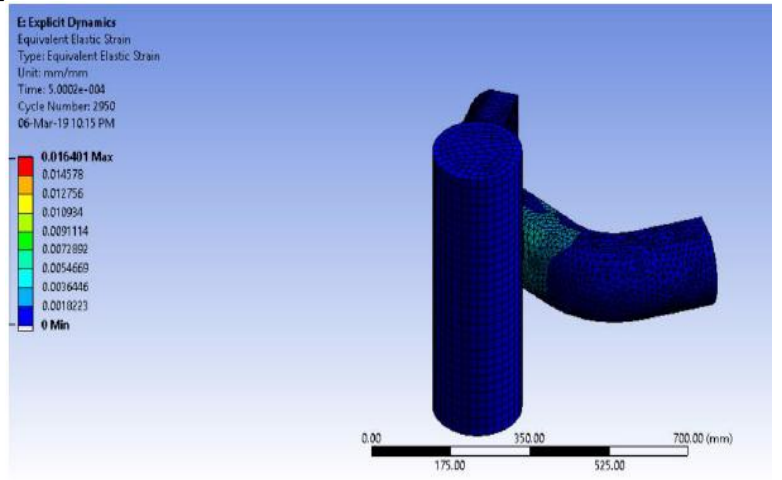

(Fig.20): Equivalent elastic strain for Aluminium Alloy material

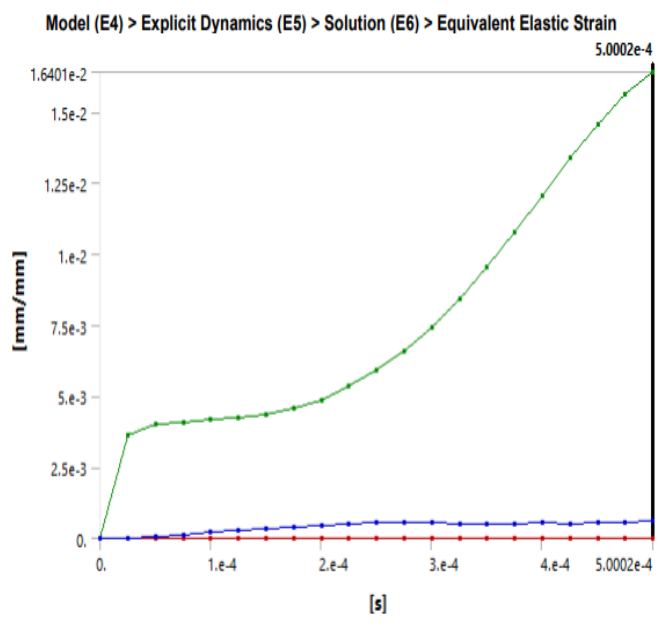

(Fig.21): Plot of Equivalent elastic strain for Aluminium Alloy material

\section{CONCLUSION:}

In this work, the bumper of a Go-Kart has been modelled and analysed using ANSYS R19.2 software. The model is analysed in various standard conditions for impact analysis using disparate materials namely POLYETHALENE, EPOXY RESIN and ALUMINIUM ALLOY. Various parameters such as total deformation, equivalent stress, equivalent elastic strain have been observed and results were noted. The robustness of the component is determined by pinpointing the fragment or chunk that the breach will occur or where the equivalent stress is elevated when force is attached in front of the Go-Kart. The impact analysis under dynamic loading shows that EXPOXY RESIN material is more reliable for Go-Kart bumper as it is producing low distortion and has low stress and strain compared to other materials used. In India bumpers are banned for various disadvantages under section 52 of motor vehicle act and $190 / 191$ of the motor vehicle act, but this work helps in conquer those negative aspects and give a roadmap for fining a better solution and safety of the passengers and the vehicle. They(bumper) additionally protect engine, fuel tank, headlamps, fog lights, indicators, etc.

\section{REFERENCES:}

1. www.ijirset.com/upload/2016/november/15_Design.pdf

2. $\quad$ citeseerx.ist.psu.edu/viewdoc/download?doi=10.1.1.554.3499\&rep=re p1\&type $=$ pdf

3. www.ijemr.net/DOC/ImpactAnalysisOfBumperAndCarChassisFrame DueToFrontalCollisionForDifferentMaterials(131-135).pdf

4. crashstats.nhtsa.dot.gov/Api/Public/ViewPublication/CDS96 